\title{
Evaluating a Program to Increase Sense of Support in Bachelor Of Science in Nursing (BSN) Students
}

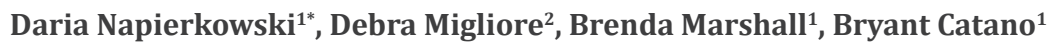 \\ ${ }^{1}$ William Paterson University \\ ${ }^{2}$ Long Island University, Brooklyn, New York
}

Received: September 27, 2017; Accepted: October 17, 2017; Published: October 23, 2017

*Corresponding author: Daria Napierkowski, Associate Professor, William Paterson University, 300 Pompton Road Wayne, NJ 07470. E-mail:napierkowskid@wpunj.edu

\begin{abstract}
Nursing education programs have a significant role in assisting students toward success. A formal peer mentoring program was designed to help the mentee receive advice and support by peer mentors. This pilot program evaluated the comfort and socialization of the student into the discipline of nursing. Results suggest that students in this program who perceived it as successful also felt more supported and had an increased comfort level in the nursing program, and therefore would be more likely to accomplish their goals as a nursing student.
\end{abstract}

Keywords: Peer Mentoring, Student Success

\section{Introduction}

Nursing students face many challenges to success in their nursing program: part time jobs, family obligations, and diverse testing styles used in nursing programs. Decreasing the barriers: language difficulties, cultural differences, lack of family encouragement, for students by providing support in the learning environment is one way to assist students in achieving success in a nursing program [5]. A mentoring relationship has benefits for the mentor as well as the mentee because there is fulfillment of witnessing a mentee succeed under one's guidance, while the mentee adapts more quickly to a new role reducing the risk of failure. Hinz found one of the factors of success in minority students is the level of confidence to succeed as they cope with stereotypes about their ability to perform [9]. A good listener can also motivate them to soar academically [9]. This article will discuss the results of a peer mentoring program evaluation and the significant relationships to student success.

\section{Background}

Beck and Srivastava recognized the impact of stress in nursing programs on student success in the early 1990's, a reality that has only increased as nurses gain responsibility for more acutely ill patients, and fewer available clinical sites in which to gain handson experience $[2,8]$. That stress factor can be further increased when the student is not the traditional student, or is a minority student, perhaps with English as a second language. This challenge is compounded by the required high stakes nursing program and licensing exams, which employ diverse testing styles and strategies [11]. Nursing students face many other social and economic challenges to achieving success in their nursing programs including the too often necessary part time jobs, multiple family obligations, and possible lack of access to transportation to and from programs. Cantwell, Napierkowski, Gundersen, Naqvi, identified learning environment support as one method to help students overcome some of the barriers to success in a nursing program [5].

Students supporting peers in a program can teach collegiality, leadership, and collaboration skills. Mentoring, which is one type of peer support, is defined as a process in which the mentor serves as counselor and friend to transfer information about how best to succeed in an organization [10]. Mentoring has traditionally been a face-to-face relationship; however, different modes of technology have been used recently, including texting or email. Mentoring programs work best when they are organized with some guidelines employed [4]. A mentoring relationship has benefits for the mentor as well as the mentee. These benefits include fulfillment of witnessing a mentee who is adapting to a new role succeed under one's guidance.

\section{Literature Review}

Abegglen and Morris reviewed a report by the UK Higher Education Academy entitled 'Mapping student-led peer learning in the UK' that outlines the challenges and opportunities of peer-led learning [1]. The two main approaches seen were Peer-Assisted Learning (PAL) and Peer-Assisted Study Sessions (PASS), typically with a second-year Undergraduate (UG) student supporting a first-year undergraduate. The report highlighted many benefits for both the first-year and second-year UG students. First-year students participating in peer-led learning experienced reduced anxiety and a greater sense of belonging, achieved higher grades, 
and developed high levels of personal and professional skills. Second-year students also acquired a high level of personal and professional skills, as well as finding that mentoring deepened their own learning and improved their grades, relationships, and inter-cultural awareness. The institutions also seemed to benefit from peer-led learning programs, though the authors conclude that further research is needed to assess the learning gains for mentors and benefits for the institute of higher education.

Budge reported a surprising lack of research on peer mentoring programs and sought to identify problems within mentoring programs in higher education [3]. Mentoring programs show tremendous benefit both in and outside of post-secondary education, particularly in helping advance careers or improving retention rates. However, the author identified several gaps in the implementation of mentoring programs. Budge argues that gender stereotypes shape the way that mentors can interact with females; women, especially Hispanic women, are less likely to be considered for mentoring [3]. Since much of the early research on mentoring involved using white men guiding white men, traditional mentoring typically excludes individuals of less represented races, ethnicities, sexual identities, and socioeconomic status, with much of the previous research not being very applicable to these individuals.

Also confounding the issue is the lack of consistency in defining mentoring programs, which leads to less valid research. Budge provides four suggestions for mentoring programs: 1) definitions of mentoring in education should be consistent and applicable to the educational setting, 2) research must be appropriate to the educational setting and incorporate empirical studies, 3) mentoring programs and research must be inclusive of women and minorities, and 4) programs must be restructured in order to become more effective [3]. To that effect, mentoring should be re-conceptualized as a holistic process that includes the perspectives of diverse populations.

Stress is a considerable psychosocial factor affecting students' performances in nursing programs. Coping efforts can be directed outward (problem-focused) or inward (emotionfocused). Problem-focused coping is affected by the Locus of Control (LOC), where students with internal LOC assume a highlevel of responsibility while those with an external LOC attributes stress to fate, chance, or other individuals. Demir, Demir, Bulut, \& Hisar conducted a quasi-experimental study to examine the effect of the mentoring program on mentees' ways of coping with stress and the LOC, and specify the students' views on the mentoring program [6]. First-year nursing students from one university were paired with fourth-year students to act as mentors for 14 weeks and completed questionnaires at the beginning and end of the study. It was found that the main sources of stress were: courses, academic standings, lecturers, future, families, friends, and accommodation. To cope with these stressors, students used active and passive ways. At the conclusion of the programs, the students' beliefs shifted from external LOC to internal LOC, with the large majority of mentees finding the mentoring program useful. Due to the change in LOC, with is associated with ways of coping with stress, problem-focused/active coping increased and emotion-focused/passive coping decreased in students. Though this represents only one nursing school, the study suggests that a mentoring program supports the mentees for problem solving, adaptation to university environment, self-awareness, self-confidence, and establishment of positive relations with their mentors [6].

Padfield and Knowles using a two-month co-mentoring pilot study describe how unregistered practitioners can contribute to the learning, support, and development of pre-registration nursing students [16]. Padfield and Knowles also present a strategy to deliver training and supervision to unregistered practitioners involved in clinical learning [16]. Unregistered practitioner mentoring associates were found to enrich the nurse mentor assessment of student performance by providing a broader perspective and were therefore an adjunct to, but not a replacement of, registered nurse mentors. It is important to define the role of the unregistered practitioner mentoring associate in relation to that of the nurse mentor. This is necessary to prevent nurse mentors from feeling undermined by what they see as enforced role drift. Further research is needed on whether the guidance of unregistered practitioner mentoring associates help nursing students prepare more effectively for registered practice.

Students' value learning collaboratively and learning with others in addition to having the opportunity to discuss leaning concerns with another student [7]. Peer mentors share their experience and help the mentee with understanding of how to best study difficult material. A peer mentor program provides good role models and is excellent training for future leaders in nursing. Many national leaders served as former peer mentors providing the best training for public service [14]. The demanding routine of a baccalaureate nursing program produces a considerable amount of stress for the student which can affect academic performance.

\section{Theoretical Framework}

The project used Kolcaba's holistic comfort theory, which postulates that when needs are met, a state of calm prevails [13]. In this study, we hypothesize that by meeting the needs of the student, the student can overcome the difficulties of a challenging nursing program. Comfort is defined for nursing as the satisfaction (active, passive, or co-operative) of the basic human needs for relief, ease, or transcendence arising from health care situations that are stressful" [12].

\section{Significance}

The researchers conducted a two year study to determine if: A supervised peer mentoring program among nursing students provided socialization into the discipline of nursing. The study 
measured comfort and socialization of the student into the discipline of nursing using an evaluation survey. The program was from September 2014 until May 2016. The evaluation was distributed to all participants. Responses to three items of the mentee evaluations were analyzed.

\section{Method}

\section{Objective}

The purpose of this study was to evaluate the impact of a supervised peer mentoring pilot program among nursing students. The research question was: Does a peer mentoring program provide socialization into the discipline of nursing?

\section{Setting and Participants}

Approval was obtained from the university institutional review board prior to data collection. The program involved voluntary participation of students that were recruited once accepted into the nursing program. Students could participate in the peer mentoring program without participating in the research project. The only requirement for students was that they be fulltime nursing students in the generic Bachelor of Science in Nursing (BSN) program. Students who volunteered to participate in the study were asked to sign a consent form prior to their involvement in the program. The descriptive statistics are presented in (Table 1).

\begin{tabular}{|c|c|c|c|c|}
\hline Cohort \# 1-3 (n= participants) & Dates & Gender \% & Age (\%) & Ethnicity/Race \% \\
\hline $1(n=9)$ & $9 / 2014-5 / 2015$ & Female $100 \%$ & $\begin{array}{l}18-25(88.9 \%) \\
26-35(11.1 \%)\end{array}$ & $\begin{array}{c}\text { Caucasian } 66.7 \% \\
\text { Hispanic } 11.1 \% \\
\text { Asian } 22.2 \% \\
\text { African Americans } 0 \% \\
\text { More than one race } 0 \%\end{array}$ \\
\hline $2(n=13)$ & $\begin{array}{l}9 / 2015- \\
12 / 2015\end{array}$ & $\begin{array}{c}\text { Female }(84.6 \%) \\
\text { Male }(15.4 \%)\end{array}$ & $\begin{array}{c}18-25(92.3 \%) \\
26-35(7.7 \%)\end{array}$ & $\begin{array}{c}\text { Caucasian } 23.1 \% \\
\text { Hispanic } 15.4 \% \\
\text { Asian } 38.5 \% \\
\text { African American } 15.4 \% \\
\text { More than one race } 7.7 \%\end{array}$ \\
\hline $3(n=7)$ & $1 / 2016-5 / 2016$ & $\begin{array}{c}\text { Female } 71.4 \% \\
\text { Male } 28.6 \%\end{array}$ & $\begin{array}{l}18-2585.7 \% \\
25-3514.2 \%\end{array}$ & $\begin{array}{c}\text { Caucasian } 85.7 \% \\
\text { Hispanic } 57.1 \% \\
\text { Asian } 42.9 \% \\
\text { African American } 14.3 \% \\
\text { More than one race } 14.3\end{array}$ \\
\hline
\end{tabular}

\section{Design}

The study utilized a longitudinal, qualitative, correlational survey design.

The overall research strategy was to initially examine the evaluation of the program by the mentees using a correlational design. This is appropriate for this pilot study to examine the two or more quantitative variables from the same group of students (mentees) to determine if there is a relationship between the two variables. The variable measured in the three questions examined from the mentee evaluation measured: success and support, support and comfort, and success and comfort. The three questions were as follows:

1. Overall, how would you rate the success of your mentor-mentee relationship?

2. Did you feel your relationship with your mentor was supportive?

3. Did participating in the mentor program increase your comfort in the nursing program?

Content analysis evaluated the responses to three items of the mentee evaluations focusing on the mentee's perception of the mentor mentee relationship success; the mentee's perception of the mentor as a supportive person; and the perceived comfort level of the mentee in the nursing program after participating in the mentor program.

\section{Data Collection}

Data were collected over a 2-year period beginning in September 2014 and ending in May 2016. Three cohorts were combined: Cohort 1 started in September 2014 and ended in May 2015, Cohort 2 started in September 2015 and ended in December 2015, and Cohort 3 started in January 2016 and ended in May 2016. The data from all 3 cohorts were combined into one dataset for a total of 29 participants $(n=29)$.

\section{Data Analysis}

The data were analyzed using SPSS IBM version 23. Kendall's Tau non-parametric statistical test was used to analyze ordinal data and a small sample size $(<30)$ [15]. Kendall's Tau is a good measure to analyze two ordinal variables as it is distribution free.

\section{Results}

\section{Demographics}

Forty two students volunteered for the program with a total of 29 mentee students that completed the program 
and submitted the mentee evaluations. The three cohorts were combined for participation analysis and demographics.

\section{Correlations}

The mentee's perception of the mentor mentee relationship success was positively correlated with the mentee viewing the relationship with the mentor being supportive $(\tau=.702, p<.05)$. The mentee viewing the mentor as supportive was positively correlated with the mentee's perceived comfort in the nursing program after participating in the mentor program $(\tau=.488, \mathrm{p}<.05)$ The mentee's perception of the success of the mentor mentee relationship was positively correlated with the mentee's perception of comfort in the nursing program after participating in the mentor program $(\tau=.452, p<.05)$.

\section{Qualitative Content Analysis}

Two mentees responded: 1 . What was most satisfying about the mentor program? "Allows students to become more involved with their peers. Allows mentors to aid younger peers to promote success in nursing-feelings of satisfaction".

2. What was least satisfying about the mentor program? "Mentor was not readily available, difficult to meet in person, did not have many questions, conflicting schedules".

Nine mentees responded: List something that you learned from your mentor:"Study techniques, test taking strategies, practice questions \& rationales, expectations of classes/projects, to never give up, not to stress over grades and GPA (grade point average), time management".

What did you like about the mentor program? "Having someone to talk to who could relate, the concept of the program, helped to learn about the nursing program, helped foster relationships".

\section{Discussion}

The findings of this pilot program reveal three statistically significant relationships further supporting the benefits of a mentor program.

The mentee's perceived success of the mentor relationship is associated with the mentee also viewing the mentor relationship as supportive. This finding supports the idea that nursing students who have mentors feel supported which may result in less anxiety and students being more empowered toward academic success.

The mentee viewing the mentor relationship as supportive was positively correlated with the mentee's perceived comfort in the nursing program after participating in the mentor program. This finding reinforces the importance of mentors to support nursing students in increasing a student's perceived comfort in the nursing program.

The mentee's perception of the success of the relationship was positively associated with the mentee's perception of comfort in the nursing program after participating in the mentor program. The third finding supports how the importance of a successful mentoring relationship is to a student's positive level of comfort in the nursing program.
Nursing students who participate in a mentee mentor relationship that the mentee perceives as successful, supportive and increases their comfort level are more likely to accomplish their goals in the nursing program. It has been shown that students that are socialized and feel comfortable in a nursing program will have decreased attrition rates, and tend to complete the nursing program [5].

\section{Limitations}

This research relied on students who were willing to participate in this study on a completely voluntary basis. The amount of students who were available to participate for the duration and respond to the evaluations resulted in a relatively small sample size. Cohort 1 was recruited for one year (2 semesters). However, mentees commented that meeting with their mentor was difficult due to the rigors of the nursing program and lost interest as the semester assignments increased. Subsequently cohort $2 \& 3$ were reduced to one semester.

\section{Implications for Nursing Programs}

Nursing programs should have mentorship programs that will enable beginner nursing students to emulate and learn from the experiences from students at a higher level who have already achieved academic proficiency at the earlier level. This pilot study built on previous research that demonstrated decreasing barriers for students by providing a supportive learning environment is one way to help students achieve success in nursing education programs [5]. Students who participated in peer assisted learning had less anxiety and developed a sense of belonging [1]. Undergraduate nursing programs are demanding and student performance is measured by rigorous testing and clinical performance. The sources of stress in a nursing program are numerous including academic standing and future concerns. Participation in a mentoring program was found to be useful to assist students to cope with stress [6]. Padfield and Knowles found unregistered practitioners also benefit students by providing another perspective to learning; however were not a replacement for registered nurse mentors [16]. Hammond, Bithell, Jones, \& Bidgood concluded that evaluation of programs to enhance student success can help improve the development of peer led learning sessions [7]. This pilot study ascertained similar results finding that mentoring improved the social aspects of learning. Further research is needed to explore further specific attributes of a successful mentorship program for nursing students. Decisions to best implement a peer mentoring program with emphasis on recruitment of students, developing schedules, and attaining funds to possibly reimburse mentors for service or finding methods of other compensation might improve outcomes. Efforts will be made in subsequent studies to recruit a larger group of students for future mentor programs and to investigate methods to motivate mentors to participate in the program.

\section{References}

1. Abegglen S, Morris A. Peer-Led Learning: Challenges and opportunities. Investigations in University Teaching and Learning. 2015;10:7781. 
2. Beck DL, Srivastava R. Perceived level and sources of stress in baccalaureate nursing students. J Nurs Educ. 1991;30(3):127-133.

3. Budge S. Peer Mentoring in Postsecondary Education: Implications for Research and Practice. Journal of College Reading and Learning. 2014;37(1):73-87. doi:- 10.1080/10790195.2006.10850194

4. Bung P. Collaborate mentoring models in higher educational institutions: A win-win strategy for mentor, mentee, and the institution. Journal of Advances in Business Management. 2015;1(3):197-203.

5. Cantwell ER, Napierkowski D, Gundersen DA, Naqvi Z. Nursing as an Additional Language and Culture (NALC): Supporting Student Success in a Second-Degree Nursing Program. Nursing Education Perspectives. 2015;36(2):121-123. doi: 10.5480/12-1007.1

6. Demir S, Demir SG, Bulut H, Hisar F. Effect of mentoring program on ways of coping with stress and locus of control for nursing students. Asian Nurs Res (Korean Soc Nurs Sci). 2014;8(4):254-260. doi 10.1016/j.anr.2014.10.004

7. Hammond JA, Bithell CP, Jones L, Bidgood P. A first year experience of student-directed peer-assisted learning. Active Learning in Higher Education. 2010;11(3):201-212.

8. Hayden J, Smiley R., Alexander M, Kardong-Edgren S, Jeffries P. The NCSBN National Simulation Study: A Longitudinal, Randomized, Controlled Study Replacing Clinical Hours with Simulation in Pre-licensure Nursing Education. The Journal of Nursing Regulation. 2014;5(2):441.
9. Hinz C. How mentoring program influence workforce diversity. Minority Nurse Fall. 2013:10-18.

10. Jeon J, Lee, J. Implementation of mentoring system in college for smooth transition to work. Proceedings of 2015 International Conference on Interactive Collaborative Learning (ICL), 20-24 September 2015, Florence, Italy. 2015. doi: 10.1109/ICL.2015.7318202

11. Khawaja N, Chan S, Stein G. The Relationship between Second Language Anxiety and International Nursing Students Stress. Journal of International Students. 2017;7(3):601-620.

12. Kolcaba KY. A theory of holistic comfort for nursing. J Adv Nurs 1994;19(6):1178-1184.

13. Kolcaba K. Taxonomic structure of comfort. 2003.

14. Minor FD. Building effective peer mentor programs. Learning Communities \&Educational Reform, summer 2007. 2007.

15. Munro BH. Statistical Methods for Health Care Research. 4th Edition: Lippincott, Williams, \& Wilkins. New York. 2001.

16. Padfield B, Knowles R. Development of learning facilitation roles for unregistered practitioners. Nurs Stand. 2014;29(16):35-40. doi: 10.7748/ns.29.16.35.e9297 